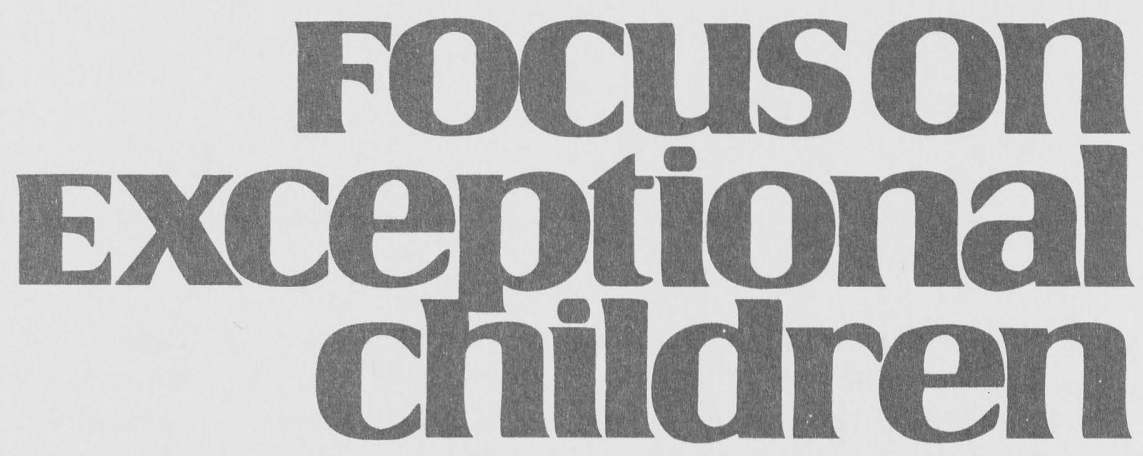

\title{
Curriculum-Based Collaboration
}

\author{
Victor Nolet and Gerald Tindal
}

\section{COLLABORATION IN SCHOOLS}

Collaboration occurs when two or more individuals work together to complete a project, create a product, or solve a problem. When people collaborate, they enter into a purposeful, goal-directed relationship with equitable contributions from all participants. In schools, collaboration could involve teachers working together to plan lessons, develop curricula, team teach, engage in peer coaching, or adapt instruction for a particular student.

When collaborative relationships develop among teachers, benefits accrue for them and for their students. Teachers gain increased opportunities to learn content, improve practice, and receive feedback. They develop a greater sense of collegiality and community, and they experience less professional isolation (Firestone \& Pennel, 1993). At the same time, peer collaboration among teachers has been identified as an effective strategy for accommodating students who have special needs in general education classrooms (Johnson \& Pugach, 1991; Phillips \& McCullough, 1990). For all of these reasons, enthusiasm continues to grow for the creation of collaborative relationships among general education and special education teachers with the goal that students who have special needs can effectively be included in general education classrooms. Given the apparent benefits of collaboration among teachers, it is surprising that it doesn't occur more regularly in schools, but, unfortunately, ongoing collaboration among teachers is still the exception rather than the norm.

Organizational as well as cultural forces work to limit both opportunities and motivation for collaboration among teachers. The physical organization of schools tends not to facilitate collaboration. Each teacher works in a separate classroom and rarely has opportunities to interact substantially with peers. Scheduling and staffing patterns in many schools also prevent development of collaborative relationships. Virtually every minute of many teachers' workdays is consumed with directly supervising or teaching students. Furthermore, to maintain adequate "coverage" of classes, teachers' planning periods often are scheduled when the individuals with whom teachers could most profitably collaborate are engaged in teaching. It is not uncommon for teachers at all grade levels to report that they

Victor Nolet is an assistant professor in the Department of Special Education at the University of Maryland. Gerald Tindal is an associate professor in the Department of Special Education at the University of Oregon. 
go through entire school days in which they have few if any conversations with other adults.

Even when schools are organized to facilitate collaboration, cultural and attitudinal factors may limit the extent to which it can occur. Many teachers lack both specific skills associated with collaboration as well as a general sense of the purpose and benefits of collaboration. Strong norms of privacy permit social interactions, but they limit discussions about teaching practice (Little, 1990). General education classroom teachers and "specialized" support personnel, such as special education teachers or school psychologists, may have different levels of training and knowledge, so that potential collaborators may not view themselves as equals.

One of the biggest barriers to effective collaboration in middle and high schools may be that the actual practice of special education differs dramatically from the practice of general education, and often there is a lack of a mutual understanding of the different roles and responsibilities different teachers fill. Indeed, special education and general education teachers working at the middle and high school levels

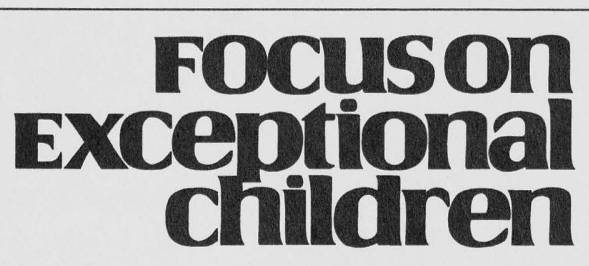

ISSN 0015-511X FOCUS ON EXCEPTIONAL CHILDREN (USPS 203-360) is published monthly except June, July, and August as a service to teachers, special educators, curriculum specialists, administrators, and those concerned with the special education of exceptional children. This publication is annotated and indexed by the ERIC Clearinghouse on Handicapped and Gifted Children for publication in the monthly Current Index to Journals in Education (CIJE) and the quarterly index, Exceptional Children Education Resources (ECER). The full text of Focus on Exceptional Children is also available in the electronic versions of the Education Index. It is also available in microfilm from Xerox University Microfilms, Ann Arbor, MI. Subscription rates: Individual, $\$ 30$ per year; institutions, $\$ 40$ per year. Copyright (C) 1994 , Love Publishing Company. All rights reserved. Reproduction in whole or part without written permission is prohibited. Printed in the United States of America. Second class postage is paid at Denver, Colorado. POSTMASTER: Send address changes to:

$$
\begin{gathered}
\text { Love Publishing Company } \\
\text { Executive and Editorial Office } \\
1777 \text { South Bellaire Street } \\
\text { Denver, Colorado } 80222 \\
\text { Telephone (303) } 757-2579
\end{gathered}
$$

Edward L. Meyen

University of Kansas

\begin{abstract}
Glenn A. Vergason Georgia State University
\end{abstract}

Richard J. Whelan

University of Kansas Medical Center may actually adhere to fundamentally different belief systems about the goals of education.

General education content teachers often enter the profession because they wish to share a commitment to and appreciation for their particular domain. For them, fidelity to their content implies that it is not enough that their students learn "anything at all" but that they learn some very specific things about a domain such as history, biology, earth science, or geography. Many content area teachers consider the learning of science, history, or math vital to an adequate quality of life for all students, and their goal in working with a special education or remedial teacher is to find ways to help students develop a deeper appreciation or understanding in a particular content area. However, because general education is oriented toward groups of students, content teachers tend to be rewarded for allocating time and expertise to ensure that the greatest number of students in their classes learn content information.

Contrast this orientation with that of many special education teachers who view requirements that students take certain content classes or pass minimal competency tests as irrelevant distractions from the goal of teaching their students to read or write more effectively or to find and keep a job. Special education teachers view success in relative terms with respect to individual students. A special educator may be less concerned that a particular student masters a particular domain such as history or biology than that the student demonstrates improved use of basic literacy or vocational functioning skills. For these teachers, the goal of working with content teachers is to find the straightest path to helping their students "get past" required classes.

\section{STATEMENT OF OWNERSHIP, MANAGEMENT, AND CIRCULATION}

Date of Filing: October 28, 1994

Title of Publication: Focus on Exceptional Children

Frequency of Issue: Monthly (except June, July \& August)

Location of Known Office of Publication:1777 S. Bellaire Street, Denver, Colorado 80222 Location of Headquarters of Publisher: 1777 S. Bellaire Street, Denver, Colorado 80222 Name and Address of Publisher, Editor, and Managing Editor: Stanley F. Love, 1777 S. Bellaire Street, Denver, Colorado 80222 Owner: Stanley F. Love

Extent and Nature of Circulation: Average No. Copies Each Issue During Preceding 12 Months

Total No. Copies Printed 2,796

Paid Circulation Sales through Dealers, etc Mail Subscriptions

Total Paid Circulation

Free Distribution

Total Distribution

Office Use and Left Over

Total

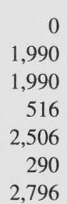

Single Issue Nearest Filing Date 2,592

0
1,929
1,929
478
2,407
185
2,592

I certify that the statements made by me above are correct and complete. 
To be effective, collaboration models aimed at supporting students who have special needs must bridge organizational and attitudinal roadblocks such as these so that special education and general education teachers can communicate effectively about content and pedagogy. Both the general educator's and the special educator's perspectives are needed. It is in the best interest of many students who have special needs to learn to use key information in the content domains. At the same time, literacy and career development must continue to be a priority for many students whose options after high school will be severely limited by diminished proficiency in basic skills in reading, written expression, and math.

\section{CURRICULUM-BASED COLLABORATION}

Curriculum-based collaboration $(\mathrm{CBC})$ is based on the notion that the expertise, perspectives, and attitudes that general education and special education teachers bring to the classroom are distinct and complementary. The model incorporates the combined expertise of special education and general education teachers in an ongoing process that focuses on specific information presented in mainstream content classes such as social studies or general science. Curriculum-based collaboration was developed by the authors in an ongoing program of research at the University of Oregon and the University of Maryland. The model has been implemented in suburban and urban middle school classrooms in the Pacific Northwest and in two large East Coast cities. Throughout the development process, general education and special education teachers have been integrally involved in formulating and field testing each component of the model.

The goal of curriculum-based collaboration is for students who have special needs to receive most of their content-area instruction from content-area classroom teachers whose background and experiences are based in a content domain such as one of the sciences or social studies. These students could include those served in special education resource room programs or other students who may be at risk of school failure, for example, those who speak English as a second language. However, $\mathrm{CBC}$ is not necessarily intended as a mechanism to facilitate full-time inclusion of all students in general education classes. Some students who have special needs may occasionally be best served in settings other than the general education classroom. Also, for some students to benefit fully from instruction in general education, special education, remedial, or other classes, support teachers may need to provide supplemental instruction in basic skills or in social skills or strategies.
With $\mathrm{CBC}$, we view the primary goal of instruction in middle and high school content classes as teaching students to think and communicate in real-world contexts (Cole, 1990; Nickerson, 1989). Achievement is defined not as acquisition of a specific body of content knowledge but as development of expertise in using that information in complex intellectual operations. For students to learn to think like historians, geographers, or biologists, they need to serve cognitive apprenticeships (Brown, Collins, \& Duguid, 1989) with content-area teachers who can model the kind of thinking used by real-world practitioners in a domain.

In curriculum-based collaboration, the content-area teacher is viewed as an expert in the domain in which instruction occurs. We realize that not all teachers, particularly in middle schools, have educational degrees in the subject matter they teach, and the actual expertise teachers bring to the classroom may vary greatly. However, when compared with a special education teacher, a general education content teacher who teaches a particular content area on a daily or weekly basis probably has a richer sense of the important information students would be expected to learn as well as anticipated performance outcomes. Therefore, we use the perceptions of the general education content teacher regarding which information is most important for students to learn as the basis for instructional planning.

Generally, curriculum-based collaboration occurs between two teachers, one of whom is a general education classroom teacher and one of whom is a special education or other support or remedial teacher. The general education and special education teachers each have specific knowledge and skills they contribute to the relationship, but they function as equal partners. The content-area teacher brings to this relationship expertise in a particular domain that permits the teacher to identify key knowledge forms (facts, concepts, principles, and procedures) around which content instruction can be organized. The special education teacher, in turn, brings pedagogical expertise related to methods for designing instruction, managing the classroom, and motivating at-risk learners. Information transfer is two-way in that both teachers are expected to gain new skills and knowledge as a result of the relationship. Interactions focus on the knowledge contained in content-area curricula, content-area pedagogy, as well as specific methods or strategies that are effective with students who have special needs.

Curriculum-based collaboration involves a combination of direct and indirect service delivery from both the general education and special education teacher, with teaching and planning responsibilities shared or divided by agreement. Content instruction occurs in the general education classroom, but 
supplemental pull-out or pull-in services may be provided in either the general education classroom or in special education settings. Often teachers engaged in curriculum-based collaboration use team or cooperative teaching, with both teachers working in one classroom; however, at times, services may be delivered in the context of a traditional resource room or remedial program. Curriculum-based collaboration is particularly well suited for use in classrooms that employ peer tutoring or cooperative learning because a wide range of activities and assessment formats typically are developed. Planning and communication meetings take place outside of instructional times, but because interactions are frequent and structured around content knowledge forms, meetings tend to be short, often lasting less than 15 minutes.

Curriculum-based collaboration consists of the six components shown in Figure 1. First the key information associated with a particular unit of instruction is identified by the general education teacher. Next, the collaborating teachers meet to clarify activities and responsibilities. After the information to be taught has been specified and activities planned, both teachers deliver initial instruction. Next, interim data are collected to assess the effectiveness of planning and instruction. Based on these data, the teachers decide whether some information needs to be retaught or reviewed during the final phase of instruction. Finally, various forms of assessment strategies are used to evaluate the overall outcomes of instruction, and this evaluation then triggers the next cycle of collaboration. Each of these components is described in detail here.

\section{Identify Key Content}

One of the problems general education and special education teachers face when they attempt to collaborate to teach content information is that they don't share a vocabulary for communicating about the content of instruction. Consider this situation:

When a special education teacher with whom we worked asked a sixth-grade general science teacher what she was planning to teach during a two-week period, the reply was "I'm going to cover Chapter 13. I'll teach fossil fuels." The special education teacher then proceeded to teach three special needs students placed in that science teacher's classroom to decode and tell the meaning of five examples of fossil fuels listed at the end of Chapter 13. However, when the authors observed in the science teacher's classroom, we found that most of the instruction centered on renewable alternatives to fossil fuels rather than examples of fossil fuels. Indeed, only one of the examples listed in the textbook was

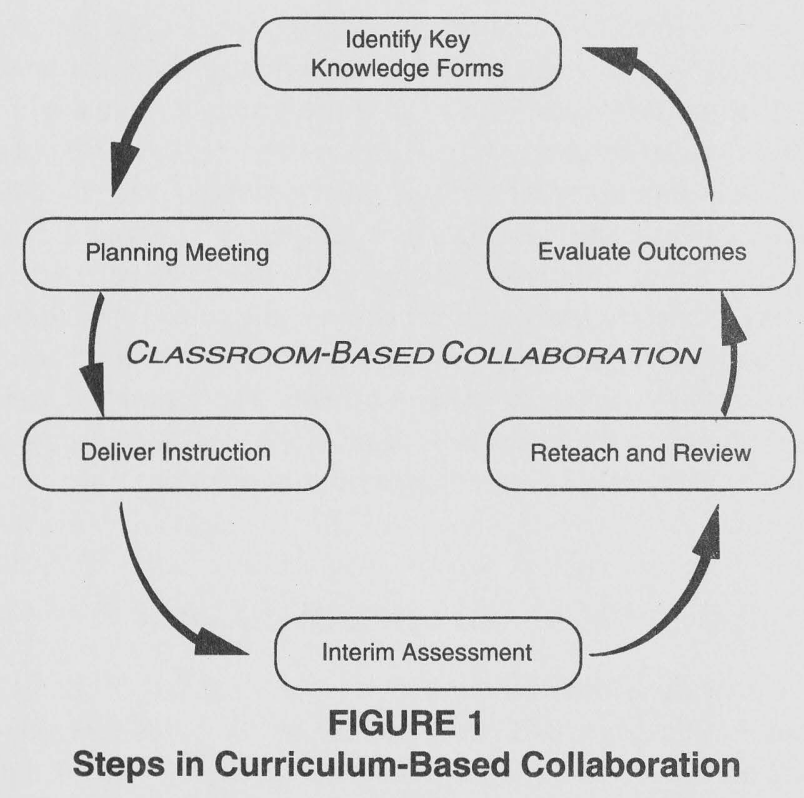

ever discussed in class. Furthermore, students spent very little time interacting with the textbook, so their ability to read and understand the vocabulary terms, although important in the larger context of literacy, was not central in developing the understanding of fossil fuels valued by the classroom teacher.

Clearly, these two teachers had very different ideas about what it meant to "teach fossil fuels" or "cover Chapter 13." The general education teacher based her instruction on her understanding of the implications of the characteristics of fossil fuels (i.e., they're nonrenewable), whereas the special education teacher based her instruction on prior knowledge of the students' skills (i.e., their reading ability was insufficient to comprehend the textbook). Neither of these approaches to "covering Chapter 13" was wrong, they were just unsynchronized. The result was that the three students with special needs were no better prepared to learn and use the information valued by their science teacher as a result of the instruction they received in special education. At the same time, they had few opportunities to practice the study skills and comprehension strategies they had been taught in the resource room.

\section{Knowledge Forms and Intellectual Operations}

To facilitate clear communication between collaborating teachers, curriculum-based collaboration employs an analysis of the conceptual knowledge contained in each unit of instruction presented in content classes. We use a taxonomy of knowledge adapted from one first presented by Roid and 
Haladyna (1982) that includes four forms of knowledge and five intellectual operations, or formats for using information. The four types of knowledge forms are facts, concepts, principles ("if-then" relationships), and procedures, which generally are formatted as a chain of principles. Information can be used in one of five intellectual operations: summarization, illustration, prediction, evaluation, and explanation.

The first step in curriculum-based collaboration is for the general education content teacher to identify the specific facts, concepts, and principles deemed critical for understanding the content of a particular unit of instruction. These key knowledge forms are then shared with the special education teacher, and together they plan activities that incorporate the intellectual operations in a range of instructional and assessment formats. By using operationalized definitions of the knowledge forms and intellectual operations, it is possible for teachers to succinctly and effectively communicate with one another about the exact information to be presented in a unit of instruction, thus preventing the kind of misunderstanding illustrated earlier.

Facts are defined as simple associations between names, objects, events, and places that use singular exemplars. For example, the statement "Columbus is the capital of Ohio" is a fact because there is only one example of the capital of Ohio. Because facts describe only one relationship, they may be grouped together in descriptions of unique events, objects, or places. In a chapter in a world geography textbook, a section describing the Indian subcontinent might include specific facts about climate and topography grouped together under the subtitle "Four Greats of India" (great rivers, great winds, great mountains, and great plateau). However, each individual fact (for example, the name of each of the rivers or the location of the great plateau) would need to be taught and remembered as a specific name or place. In this respect, facts may not be difficult to teach or test but they are especially difficult to learn because they must be memorized and have little explanatory power beyond the specific relationship they describe.

Concepts are clusters of events, names, dates, objects, and places that share a common set of defining attributes or characteristics. A concept may be thought of as a category having a rule that defines its relevant characteristics, a name, and a set of instances or exemplars that share the key attributes. In this definition, rules provide the basis for organizing the attributes of the concept; these attributes, in turn, provide the criteria for distinguishing examples of the concept from nonexamples. This is a classical view of concepts that does not cover every contingency encountered in content classes, but it does provide a framework within which teachers can share information about what should be taught and how to teach it. Indeed, many concepts encountered in content classes are quite complex, with conditional or nested attributes or membership in multiple categories. When such concepts are targeted, collaborating teachers must clarify attributes and examples through discussion during the planning meeting.

Principles indicate causal or covariant relationships among different facts or concepts, more often the latter. A principle usually represents an if-then or cause-effect relationship, although this relationship may not be stated explicitly. A principle generally involves multiple applications in which the fundamental relationship among the relevant concepts is constant across virtually all examples of the concepts. For example, the law of supply and demand may be taught as the principle "when supply goes up, demand goes down," with comparable applications found in the contexts of medieval European city-states, a child's lemonade stand, and the 1929 stock market crash.

Procedures involve the steps or phases required to complete a process. For example, the topic "Scientific Method" may be taught in seventh-grade science class as a series of steps proceeding from formation of a hypothesis, construction of an experiment, collection of data, and evaluation of results. However, procedural knowledge involves more than simply "knowing what" the steps are, but focuses on "knowing how" to execute those steps in an actual experiment (Anderson, 1983). Often procedures can be formatted as a set of principles that comprise a decision chain of the form "If A occurs, then I do B. If C occurs, then I do D." Execution then follows a series of decisions based on results obtained at each preceding step. For example, writing a research paper might involve a series of decisions about where to obtain information, which information to include, and the order in which information should be presented.

Concepts and principles form the bedrock of curriculumbased collaboration. Concepts have greater explanatory power than facts in that they can be broad enough to be applicable across multiple contexts within a domain but often are specific to a particular body of content. Similarly, while there may only be one or two key principles associated with a body of content or domain, they may link together as many as eight or ten key concepts in a few overarching relationships. Knowing the attributes and examples of the key concepts then sets the occasion for understanding the principles.

Concepts and principles can be used in a wide range of intellectual operations. These operations are arranged in increasing complexity, where summarization represents a less complex operation and prediction, evaluation, and explanation 
represent higher levels of complexity. Summarization is either a near-verbatim reproduction or a paraphrase (rewording or condensation of specific content previously presented in instruction). Illustration is generation or identification of an example of a concept or principle that was not presented previously during instruction. Because the student must attend to the key attributes or relationships of the concept or principle rather than simply recall an example presented during instruction, illustration involves the manipulation of information rather than simple recall. Prediction is description of a likely outcome, given a set of antecedent circumstances or conditions. Evaluation is analysis of a problem that requires a judgment to make a decision. Evaluation is a two-step process in which the student first makes a decision and then supports it with a rationale or an argument. Explanation is description of the antecedent circumstances or conditions that would be necessary to bring about a given outcome. Explanation is the reverse of prediction. The student must use information about a concept or principle to work backwards from the circumstances presented and tell what happened to create it.

\section{Content Planning Worksheet}

Using the framework just described, the general education teacher identifies the most important concepts and principles associated with a unit of instruction that is expected to last two to three weeks. This information is then summarized on a content planning worksheet that is shared with the special education teacher with whom she or he is collaborating. An example of a content planning worksheet for a unit on Europe in the Middle Ages is shown in Figure 2.

This form has three components that specify (a) the proposed schedule for instruction, (b) key knowledge forms that the teacher considers minimally essential for understanding the unit of instruction, and (c) activities and specific tasks that represent the outcomes expected to result from instruction. The general education content teacher completes the top two sections of the form, and the collaborating teachers work together to specify activities and tasks during the content planning meeting.

The schedule identifies the specific topic or unit that will be taught during a two- to three-week period, and the specific topic or activities that will be taught each day. In middle schools, this amount of time usually corresponds to one or two chapters in a typical content-area textbook. At the high school level, it might correspond to a unit consisting of two to four chapters. The goal is to make the schedule realistic in terms of comprehensiveness but not so full of information that planning becomes impossible. At the same time, schedules that focus on too little content or too short a period of time are unnecessarily labor intensive when additional planning worksheets must be completed or planning meetings held.

Typically, content teachers identify eight to ten key concepts and one or two principles in middle school classes and slightly more in high school classes. Many of the contentarea teachers with whom we have worked have had difficulty in deciding what are the most important concepts or principles in a unit and subsequently in specifying the attributes of those knowledge forms. Their tendency often has been to include too much factual information (for example, names, dates, etc.) or to identify broader themes that have indefinite attributes or examples rather than specific concepts or principles. However, as teachers have become more comfortable with the framework of knowledge forms and intellectual operations presented here and as they engage in more conversations with other content teachers and special education teachers, they have tended to identify more focused lists of concepts and principles.

Outcomes are framed in the form of intellectual operations. For example, a teacher may wish to have students generate examples of (i.e., illustrate) key concepts or make predictions using key principles. On the content planning worksheet, outcomes are listed as activities and tasks. Instructional activities are the specific instructional and assessment events that take place during the two- to three-week period during which the unit is taught. Generally, activities are associated with specific materials such as the textbook or worksheets. Planning tasks refer to the things each teacher will do to help students accomplish the activities. On the planning worksheet shown in Figure 2, the initial of the teacher responsible for each task is included in parentheses after each task statement, as determined during the planning meeting.

In a sense, the content planning worksheet represents an agreement that is negotiated between the collaborating teachers. The knowledge forms and expected outcomes listed on the content planning worksheet represent the minimal requirements of performance for mastery of the topic covered in the two- to three-week unit. If a student is able to use the concepts or principles listed in the intellectual operations specified in the activities and tasks, then both teachers will agree that the student has mastered the topic. A more formal variation on this theme was described by Tindal and Germann (1991), where mainstream consultation agreements were used to specify the grade a student could earn and the responsibilities of the general and special education teachers and the student for ensuring that the student demonstrates sufficient mastery of secondary content material.

The content planning worksheet should function as a thumbnail sketch rather than a detailed blueprint of instruc- 


\section{CONTENT PLANNING WORKSHEET}

\begin{tabular}{|c|c|c|c|c|c|}
\hline Teachers Smithers/Newhall & Class & s World Histor & & Begin Date $\Lambda$ & ovember 14 \\
\hline \multicolumn{6}{|c|}{ SCHEDULE } \\
\hline Topic & MONDAY & TUESDAY & WEDNESDAY & THURSDAY & FRIDAY \\
\hline Middle Ages & & $\begin{array}{l}\text { When were the } \\
\text { Middle Ages? }\end{array}$ & $\begin{array}{l}\text { Life on the } \\
\text { manor }\end{array}$ & $\begin{array}{l}\text { Serfs, vassals, } \\
\text { lords, knights }\end{array}$ & Quiz \\
\hline \multirow[t]{2}{*}{ City-States } & City-states & $\begin{array}{c}\text { Travel between } \\
\text { city-states }\end{array}$ & The economy & Quiz & Coat of arms \\
\hline & Make a shield & The plague & Castles & Review & Test \\
\hline
\end{tabular}

KNOWLEDGE FORMS

Attributes/lf

Examples/Then

Trade

Castle

Knight

Plague
An exchange of goods/buying and selling Imports/exports

A fortified group of buildings held by a vassal or a ruler in feudal societies

Windsor Castle Examples on page 85

Soldier or armored horseman

A trained, armored horseman who fought wars in the early Middle Ages

A widespread sickness

Bubonic plague in Europe in the 1340s AIDS

\section{ACTIVITIES AND TASKS}

Instructional Activity

\section{Reading}

Chapter 12, section 1

Chapter 12, section 2

Projects

Make a shield with coat of arms

\section{Assignments}

Questions on page 97

Report: What did knights do?

Worksheets

How were castles constructed?

Assessments

Evaluation essay: Middle Ages

vs. now, tell why. Test.
Planning Tasks

Study guide for Chapter 12: Key concepts (S)

Model illustration and evaluation of concepts $(N)$

Study strategies for researching coat of arms (S)

Review key attributes of city-state and knights (S)

Short evaluation essay on knight vs. Iord (N)

Review attributes of castle (S)

November 21

Make up three practice essays for review (S)

Review attributes of key concepts (S)

Make up test items ( $S$ \& $N)$

Due Date

November 17

November 22

November 20

November 16

November 20

FIGURE 2

Content Planning Worksheet 
tion in a content classroom. The general topic and overall content should remain stable, but the day-to-day activities can vary according to the needs of the teachers and students. As the collaboration process becomes more comfortable for the collaborators, the content planning worksheet actually functions more as a proposal, with specific details to be worked out during a face-to-face planning meeting. This is particularly true with respect to the outcomes and activities listed on the lower part of the form. The content teacher suggests expected outcomes, but the specific instructional activities and planning tasks get worked out during a planning meeting.

\section{Planning Meeting}

After the general education content teacher has identified the key knowledge forms and desired outcomes for the unit of instruction, the form is shared with the special education or remedial teacher collaborator and a meeting is scheduled. The purpose of the meeting is to finalize the schedule of instruction, clarify the attributes and examples associated with the knowledge forms, and plan the activities and tasks that will be implemented.

Depending on the nature of the relationship that has developed between the collaborating teachers, the planning meeting may be quite informal or fairly structured. When two teachers have been working together for some time, are in agreement about the nature of the knowledge forms to be targeted, and have established norms and responsibilities for designing and implementing instruction, planning meetings can be as brief as 10 minutes and take place "on the fly" after or before school or over lunch in the teachers' lounge. When two teachers are just beginning to collaborate, they may need to invest more time during planning meetings developing consensus about the nature of facts, concepts, and principles, and clarifying attributes and examples. Some teachers find it useful to hold planning meetings in installments, where the first session focuses on the key knowledge forms and subsequent meetings focus on planning activities and assessment tasks that use complex intellectual operations. This arrangement keeps the amount of time devoted to any one meeting to a minimum. In the early stages of development of a collaborative relationship among two teachers, it is useful to use a checklist such as the one illustrated in Figure 3 to structure the meeting. Such a form helps to keep the meeting focused on the key information that must be shared and ensures that the critical instructional activities, assessment formats, and planning tasks are discussed.

The key tasks to be accomplished during the planning meeting are shown on the checklist. These focus on comple- tion of the content planning worksheet, but also include explicit reference to the areas that must be agreed upon during the collaboration process. Specifically, the teachers must decide what intellectual operations will be modeled or prompted in the various activities and tasks. For example, in a unit on plate tectonics, collaborating teachers might decide whether students would be required to simply recognize examples of different types of faults or evaluate the potential damage various faults could cause in a specific scenario.

Development of a timeline for completion of assignments and tasks is the final task to be accomplished during the planning meeting. This step ensures that the teachers' instruction stays coordinated throughout the unit and is especially important if instruction is delivered in separate settings. On the content planning worksheet, the column labeled "Due Date" specifies the schedule of events.

\section{Deliver Instruction}

To the maximum extent possible, students who have special needs are expected to participate in the general education classes, with supportive services scheduled at another time during the day. Therefore, much of the instruction delivered in curriculum-based collaboration takes place in the general education classroom, with special education and general education teachers working cooperatively to plan and provide instruction for all students in the class. They may coteach, with each collaborator taking responsibility for some aspect of instruction, or they may run separate groups in the same classroom.

However, CBC does not necessarily imply that all lessons are delivered with both teachers working in the general education classroom. Scheduling constraints or the preferences of the collaborating teachers may result in support services being delivered in settings outside the content classroom. For example, in many middle and high schools, during any one class period, students scheduled into a resource room may represent different grade levels and take a variety of content classes. It would be impossible for the special education teacher to co-teach in a content class during this period.

When students do receive assistance in another setting during the class period, the collaborating teachers plan activities and tasks to ensure that students don't miss new information presented in the general education classroom. For example, the class may be scheduled to work individually on reports or projects or pursue an enrichment activity not directly related to the key knowledge forms. Supportive instruction provided by a special education or remedial teacher focuses primarily on the key knowledge forms and intellec- 
Date of Meeting

PLANNING MEETING CHECKLIST

Teachers

\begin{tabular}{|l|l|l|l|}
\hline \multicolumn{1}{|c|}{ Task } & Yes/No & Comment \\
\hline Topic Identified & yes & no & \\
\hline Schedule Outlined & yes & no & \\
\hline Knowledge Forms Identified & yes & no & \\
\hline Attributes/Examples Identified & yes & no & \\
\hline Reading Tasks & yes & no & \\
\hline Problem-Solving Tasks & yes & no & \\
\hline Assignments Specified & yes & no & \\
\hline Final Test Discussed & yes & no & \\
\hline Grading Negotiated & yes & no & \\
\hline Pull-Away Schedule Discussed & yes & no & \\
\hline Student Reminders & yes & no & \\
\hline Notes: & & & \\
\hline
\end{tabular}

\section{FIGURE 3}

Planning Meeting Checklist

tual operations targeted on the content planning worksheet. At the same time, while instruction in the general education classroom may involve additional information or activities, the key knowledge forms represent the basis for all other instruction. Naturally, the exact methods of instruction, specific activities, curriculum materials, and so on vary from teacher to teacher; however, supportive services provided by a special education or remedial teacher tend to be effective when they are aimed at (a) previewing, (b) modeling, (c) providing practice in using key knowledge forms, and (d) reviewing the key knowledge forms.

Previewing involves teaching students who have special needs the attributes and examples of key concepts and principles before they are presented to the rest of the class. Previewing provides students with two advantages. First, students have the maximum amount of time possible to learn and practice using the concepts and principles associated with a unit, particularly, complex or abstract information that might be difficult to master. Second, when a particular concept is then presented in the general education classroom, the student already is familiar with it and can participate more fully in class discussions or benefit from demonstrations or explanations presented by the general education teacher. Previewing can be particularly effective when the general education teacher subsequently models the key knowledge forms during instruction and provides students with opportunities to practice using them in complex intellectual operations (Nolet \& Tindal, 1994).
Modeling occurs when teachers model the use of key concepts in complex intellectual operations. Their students tend to use those concepts more frequently in authentic problemsolving tasks and they tend to answer correctly test items that pertain to those concepts (Nolet \& Tindal, 1993). Teachers can model the use of key knowledge forms in each of the intellectual operations by posing questions or scenarios and then engaging in a think-aloud process to make the thinking process visible for students. Here is an example of an instructional dialogue that models the intellectual operation evaluation with the concepts of fossil fuels, acid precipitation, and nonrenewable energy:

Teacher: Newtopia is a planet in a galaxy not far from here. The people who live there have just discovered fossil fuels. Should they develop them or not?

Student: Well ... Yeah, I guess so .... .

Teacher: Fossil fuels are formed over millions of years when trees and animals decay and are placed under tons of pressure. Fossil fuels are nonrenewable. When they are used up, there are no more. If the people develop the fossil fuels, they will run the risk of creating air pollution and acid precipitation. Also, they could run out of fossil fuels. No one on Newtopia knows how much fossil fuel they have. On the other hand, they could develop the fossil fuels and have a 
much higher quality of life. They could have all the modern conveniences we have. This would give them more time to create music and art and go to school. We would have to decide which is better: to have a clean planet like the people of Newtopia have now or to have a higher quality of life like we have now.

Development and administration of frequent practice activities are critical tasks for the teacher providing supplemental support. Practice activities could be in the form of short problem-solving tasks requiring a written or oral response, questions that prompt intellectual operations, or other activities such as worksheets or cooperative learning activities. Often, when one of the collaborating teachers develops practice activities, they are implemented in the general education classroom, and they provide a powerful interface between the general and special education programs.

Reviewing occurs when a teacher reteaches the key concepts or principles after they have been presented in the general education content class. Reviewing can occur any time in the unit after a knowledge form has been taught in the general education class and involves explicit reteaching of the key information. For example, if a general education science teacher taught the attributes of a fossil fuel during class on Monday, the special education teacher might ask students to give an example and attributes of fossil fuels on Wednesday. Ideally, the collaborating teachers time the presentation of new material in the general education classroom with supportive previewing, modeling, and reviewing so students, in effect, receive massed practice in using key knowledge forms.

\section{Interim Assessment}

To support ongoing communication and instructional planning, teachers using curriculum-based collaboration collect information about student learning on an ongoing basis throughout the two- to three-week period a unit is taught. Measures can include short problem-solving tasks that require students to use key knowledge forms in complex intellectual operations or perception probes in which students list the terms they think are most important for understanding the topic being taught (Tindal \& Nolet, in press). Other interim measures that can contribute to instructional decision-making include informal observations and traditional criterion-referenced quizzes that require students to summarize or illustrate key knowledge forms. Interim assessments can be administered to the entire class or to a subgroup of students and usually are administered after about one third to one half of the information that is to be taught in the unit has been presented. They usually focus on the knowledge forms and intellectual operations the collaborating teachers view as most important in the instruction that has been delivered to that point. Responsibility for developing, administering, and scoring the interim assessments is finalized in the initial planning meeting.

\section{Problem-Solving Tasks}

Problem-solving tasks require students to apply the targeted facts, concepts, principles, and procedures in one of the intellectual operations described earlier by making predictions or decisions or developing explanations. Students might be asked to respond in writing with a brief essay or orally in a short interview. Generally, interim problem-solving tasks take no more than 10 minutes to administer. Scoring is conducted using holistic sorting or analytic rating scales focusing on the accuracy and effectiveness of students' use of the key knowledge forms. The intent of interim problemsolving tasks is to inform instruction by revealing student misconceptions or factual errors, and they are not used to grade student performance or generalized learning.

\section{Perception Probes}

Perception probes focus on students' opinions of which information they view as most important for understanding the content of instruction, regardless of their actual comprehension of content. Perception probes are administered one or two times during a unit and take approximately 10 minutes. Students are simply asked to list the most important words and ideas in the unit. Scoring involves tallying the most frequently occurring words and the targeted knowledge forms on the perception probes completed by the class. Perception probes permit the collaborating teachers to check the alignment of student perceptions with their own goals for instruction. If it turns out that very few students list as important the terms the collaborating teachers want them to understand, instruction needs to focus student attention on those terms specifically. On the other hand, if student perceptions about which information is most important match the teachers', the instructors can present additional knowledge forms or use information in more complex intellectual operations.

\section{Reteach and Review}

Based on the information collected during interim assessments, the collaborating teachers hold at least one interim 
planning meeting in which they finalize plans for instruction for the remainder of the unit. This meeting is analogous to the high altitude camp climbers establish before their final assault on the summit of a very high mountain. The collaborating teachers review the content planning worksheet to adjust the schedule and to jettison or reprioritize the knowledge forms and activities and tasks they expect to accomplish. During the remainder of the time the unit will be taught (that is, the final assault on the summit), instruction will focus on the most important knowledge forms and on that information about which students seem to have the weakest understanding.

As with the initial planning meeting, some of the teachers with whom we have worked have used a fairly formal meeting process, employing a meeting checklist similar to that shown in Figure 3, while others have developed informal methods for sharing information. Interim planning meetings generally are held after about two-thirds of the content has been presented.

During the final phase of instruction, when information is reviewed and retaught, collaborating teachers often arrange to co-teach some of the lessons. This allows both teachers to obtain "on-line" information about student learning and to deliver instruction in small groups of various configurations based on students' needs and understandings. It is particularly useful during this final phase of instruction for the teachers to model use of information in complex intellectual operations and for students to have adequate practice, with feedback, in using key information and intellectual operations. Therefore, the teachers may arrange more hands-on problem-solving tasks, peer tutoring, or cooperative learning activities during this time.

\section{Evaluate Outcomes}

The final phase in curriculum-based collaboration is to collect student performance data to evaluate the effectiveness of instruction. Measures can include more elaborate versions of the problem-solving tasks used in interim assessments and criterion-referenced tests that focus on the key knowledge forms used in various intellectual operations (Roid \& Haladyna, 1982). Generally, development of outcome measures is a collaborative process, with both collaborating teachers contributing tasks or test items and assisting with scoring. Outcome data can be evaluated using a normreferenced perspective in which the overall performance of the class is summarized or an individual-referenced perspective in which the performance of specific students is compared over time.
In a norm-referenced perspective student performance can be summarized by knowledge form. In our work we have used the average item easiness (i.e., percentage of students who passed each item) for all items pertaining to specific concepts. For example, suppose an assessment task administered to a class of 20 students contains three items that pertain to the concept "dual economy." The items are passed by 18,15 , and 20 students, respectively. The first item has an easiness of .90 , the second an easiness of .75 , and the third an easiness of 1.0. Thus the easiness rating for the concept "dual economy" is .88. This easiness rating can be compared with that for other concepts tested, and the teachers can develop a profile of the extent to which each concept was mastered by the class.

We also have used short essays and brief interview tasks in norm-referenced perspective. Students are presented with a task employing one of the intellectual operations that involves manipulation of information, such as evaluation or explanation. These tasks are then scored using an analytic scoring system that rates students' effectiveness in making a decision and supporting it with content information (Nolet $\&$ Tindal, in press). Normative data can involve these qualitative ratings as well as the frequency with which students use targeted concepts in essays or oral responses. If the class masters a sufficient number of key knowledge forms in a desired range of intellectual operations, instruction can move on to the next unit. If performance does not meet teacher expectations, the collaborating teachers can decide whether to modify instruction or reteach certain information.

In an individual-referenced perspective, the performance of a particular student is compared with her or his previous performance on similar tasks. Growth over time is evaluated, using a time-series approach to data analysis. We have used two measures of student learning in individual-referenced evaluations. One is performance on targeted concepts on criterion-referenced tests. For example, if a student answers correctly two out of the three items pertaining to "dual economy" on the test in the previous example, her score for that concept would be $67 \%$. If the test samples four other concepts, for which she receives scores of $100 \%, 90 \%, 50 \%$, and $75 \%$, her combined concept score is $76 \%$ for that unit. Concept scores can be plotted for each unit to observe whether she is maintaining an adequate level of performance. Because the content changes with each unit, decision rules may be tied to maintenance of a particular level of performance (for example, at least $75 \%$ ) rather than to a rate of growth as might be the case with curriculum-based measures (Fuchs \& Deno, 1991).

The second individual-referenced measure we have used 
is student ratings on use of intellectual operations on problem-solving tasks such as interviews or essays. This rating is then plotted and compared with ratings on previous tasks that required the same intellectual operation. For example, a student's performance in using social studies content to make a decision and support it with a cogent rationale can be evaluated by comparing tasks that require the intellectual operation of evaluation. Again, because the scale contains only five anchors, and because the content of units is constantly changing, we are more interested in observing whether students "hold their own" and show growth over longer periods of time than on short-term growth. However, it is possible to make valid decisions about the success of a student in a content class by systematically evaluating their growth in complex thinking within the context of specific content material.

\section{MAKING COLLABORATION WORK}

For curriculum-based collaboration to be successful, it must be implemented in an environment in which there exists a collaborative ethic. According to Phillips and $\mathrm{McCul-}$ lough (1990), in an organization where this ethic exists, all professionals share joint responsibility for problems as well as joint accountability and recognition for problem solution. A collaborative ethic involves a belief that pooling talents and resources is advantageous and that the outcomes of collaboration are desirable (Phillips \& McCullough, 1990).

Clearly, the kind of collaborative relationships we have described here do not develop overnight, and in schools where collaboration is not currently occurring, considerable time and energy will need to be expended to gain peer and administrative support for such efforts. We offer the following suggestions for those interested in initiating curriculumbased collaboration:

1. Gain administrative support. In schools where a collaborative ethic doesn't yet exist, organizational barriers may prevent individual teachers from going beyond small-scale collaboration efforts. However, when building and district administrators understand and support the goals of collaborative service delivery, organizational barriers can be addressed at the system level. Keep administrators informed of the goals of collaboration and share data that demonstrate success.

2. Begin small. Work with one teacher on one unit and with a few students. As relationships develop, more elaborate interventions can be tried.
3. Collect data regularly that can support valid inferences about student performance in content classes. Perception probes or short problem-solving tasks can be administered to individual students or classes, even when collaboration isn't ongoing. These data can serve as the basis for beginning a conversation with potential collaborators.

\section{REFERENCES}

Anderson, J. R. (1983). The architecture of cognition. Cambridge, MA: Harvard University Press.

Brown, J. S., Collins, A., \& Duguid, P. (1989). Situated cognition and the culture of learning. Educational Researcher, 18(1), 32-42.

Cole, N. S. (1990). Conceptions of educational achievement. Educational Researcher, 19(3), 2-7.

Firestone, W. A., \& Pennel, J. R. (1993). Teacher commitment, working conditions, and differential incentive policies. Review of Educational Research, 63, 489-525.

Fuchs, L. S., \& Deno, S. L. (1991). Paradigmatic distinctions between instructionally relevant measurement models. Exceptional Children, 57, 489-500.

Johnson, L. J., \& Pugach, M. C. (1991). Peer collaboration: Accommodating students with mild learning and behavior problems. Exceptional Children, 57, 454-455.

Little, J. W. (1990). The persistence of privacy: Autonomy and initiative in teachers' professional relations. Teacher College Record, 91(4), 509 534.

Nickerson, R. S. (1989). New directions in educational assessment. Educational Researcher, 18(9), 3-7.

Nolet, V. W., \& Tindal, G. (1993). Special education in content classes: Development of a model and practical procedures. Remedial and Special Education, 14(1), 36-48.

Nolet, V. W., \& Tindal, G. (1994). Instruction and learning in middle school science classes: Implications for students with learning disabilities. Journal of Special Education, 28, 166-187.

Nolet, V. W., \& Tindal, G. R. (in press). Essays as valid measures of learning in middle school science classes. Learning Disabilities Quarterly.

Phillips, V., \& McCullough, L. (1990). Consultation-based programming: Instituting the collaborative ethic in schools. Exceptional Children, 56, 291-304.

Roid, G. H., \& Haladyna, T. M. (1982). A technology for test item writing. New York: Academic Press.

Tindal, G., \& Nolet, V. W. (in press). Serving students with learning disabilities in middle school content classes: A descriptive study of critical variables linking instruction and assessment. Journal of Special Education.

Tindal, G. R., \& Germann, G. (1991). Mainstream consultation agreements in secondary schools. In G. Stoner, M. Shinn, \& H. Walker (Eds.), Interventions for Achievement and Behavior Problems. Washington, DC: National Association of School Psychologists.

Preparation of this article was supported in part by the U.S. Department of Education, grant number HO23A20047. Opinions expressed herein do not necessarily reflect the position or policy of the U.S. Department of Education and no official endorsement by the Department should be inferred. 